\title{
Pulse jet electrodeposition of nanocrystalline copper and its application as an electrical discharge machining electrode
}

\author{
Hui Fan ${ }^{1, *}$, Yangpei Zhao ${ }^{2}$, Jie Jiang ${ }^{3}$, Shankui Wang ${ }^{1}$, Wei Shan ${ }^{1}$, Rulin Ma ${ }^{1}$ \\ ${ }^{1}$ School of Mechanical and Electrical Engineering, Jiangsu Normal University, Xuzhou, 221116, China \\ 2 Jiang su Jiangzhu Institute, Xuzhou, 221116, China \\ ${ }^{3}$ Jiangsu Key Laboratory of 3D Printing Equipment and Application Technology, Nantong Institute of \\ Technology, Nantong, 226002, China \\ *E-mail: xzfanhui@163.com
}

doi: $10.20964 / 2020.03 .60$

Received: 25 November 2019 / Accepted: 7 January 2020 / Published: 10 February 2020

\begin{abstract}
A nanocrystalline copper electrode material was fabricated using the pulse jet electrodeposition method on a stainless steel rod. The microstructure evolution and grain size were examined using scanning electron microscopy and X-ray diffraction. The nanocrystalline copper had a fine microstructure comprising nanosized grains with a size of $28 \mathrm{~nm}$ at a peak current density of $400 \mathrm{~A} / \mathrm{dm}^{2}$ and a pulse duty circle of 1:6. An electrode material mass loss experiment was conducted between the nanocrystalline copper electrode prepared by pulse jet electrodeposition and a conventional electroformed coarse copper electrode. The results show that the relative mass loss factor of the pulse jet electrodeposited copper electrode was obviously lower than that of electroformed coarse copper and reached a minimum value of $0.25 \%$ with an applied EDM peak current density of $3 \mathrm{~A} / \mathrm{dm}^{2}$.
\end{abstract}

Keywords: Electrode performance; pulse jet electrodeposition; nanocrystalline copper

\section{$\underline{\text { FULL TEXT }}$}

(C) 2020 The Authors. Published by ESG (www.electrochemsci.org). This article is an open access article distributed under the terms and conditions of the Creative Commons Attribution license (http://creativecommons.org/licenses/by/4.0/). 